\title{
Downscaling of weather generator parameters to quantify hydrological impacts of climate change
}

\author{
Jie Chen ${ }^{1, *}$, François P. Brissette ${ }^{1}$, Robert Leconte ${ }^{2}$ \\ ${ }^{1}$ Department of Construction Engineering, École de technologie supérieure, Université du Québec, \\ 1100 Rue Notre-Dame Ouest, Montreal, Québec H3C 1K3, Canada \\ ${ }^{2}$ Department of Civil Engineering, Université de Sherbrooke, 2500, boul. de l'Université, Sherbrooke, Québec J1K 2R1, Canada
}

\begin{abstract}
A major obstacle in quantifying the hydrological impacts of climate change is the mismatch between the coarse resolution of climate model outputs (general circulation models and regional climate models) and the fine resolution requirements of hydrological models. This research presents a statistical downscaling approach combining the attributes of both the stochastic weather generator (WG) and the change factor (CF) method to overcome this problem. It is further compared against the commonly used CF method in terms of quantifying the hydrological impacts of climate change over the next century for a Canadian watershed (Quebec Province). Both downscaling methods suggested increases in winter (November-April) discharge and decreases in summer (June-October), especially for those downscaled by the WG-based method. The WG-based method predicted higher peak discharges than the CF method. The 2 downscaling methods suggested significantly different increases in annual and seasonal discharges, particularly for low flows. Hydrology results show that precipitation and temperature variability play a very important role in the runoff generating process, and that neglecting to address this variability can lead to biased results. In particular, the WG-based method has a significant advantage in simulating low flows because it takes into account the change of precipitation occurrence. The results also outline the uncertainty linked to the choice of a downscaling method.
\end{abstract}

KEY WORDS: Statistical downscaling - Stochastic weather generator - Change factor method · Hydrology $\cdot$ Climate change

\section{INTRODUCTION}

There is substantive empirical evidence showing that the frequency of rainy days and heavy precipitation events increased during the last century for North America (Groisman et al. 2005, Pryor et al. 2009). The Intergovernmental Panel on Climate Change (IPCC 2007) stated that the average surface air temperature of Earth will likely increase between 1.8 and $4.0^{\circ} \mathrm{C}$ by the end of this century and that the variability of precipitation will also be on the rise. Climate change will affect the global hydrological cycle and, consequently, assessing the changes in future precipitation (quantity and variability) is a priority. Quantifying the impacts of climate change requires a tool or an approach that is able to produce climate projections. General circulation models (GCMs) have been developed to meet this requirement. However, the spatial and temporal resolutions of current GCMs are too coarse to assess the watershed and site-specific impacts of climate change (IPCC 2007). Even though daily-scale data is available for some GCMs, it is still unsuitable for medium and small watersheds, as well as for site-specific impact studies in the current form. For example, precipitation simulated by climate models usually has 
too many small events resulting in an overestimation of the wet day frequency, as well as biases resulting in an under/overestimation of the mean annual precipitation (Rivington et al. 2008). Dynamical and statistical downscaling methods have been developed to resolve this issue. Dynamical downscaling was developed based on dynamic formulations using the initial and time-dependent lateral boundary conditions of GCMs to achieve a higher spatial resolution by nesting regional climate models (RCM) (Caya \& Laprise 1999). The spatial resolution of RCMs are much higher than that of GCMs. However, the resolution remains too coarse for small and medium-sized watersheds as well as for site-specific impact studies. Moreover, RCM data is only available for limited regions, due to the large computational cost of running the models (Solman \& Nunez 1999). To overcome this problem, statistical downscaling methods have been developed. These involve linking the states of some variables representing a large scale (GCM or RCM grid scale, predictors) to the states of some variables representing a much smaller scale (catchment or site scale, predictands). A range of statistical downscaling methods have been developed and can be classified into 3 categories: transfer function (Wilby et al. 1998a, 2002a), weather typing (von Storch et al. 1993, Schoof \& Pryor 2001) and weather generator (WG)-based approaches (Wilks 1992, 1999, Zhang 2005, Qian et al. 2005, 2010, Kilsby et al. 2007). Each category has its advantages and drawbacks. For transfer functions and weather typing schemes, the main drawback is that they usually lack strong and stable correlations between predictors and predictands, especially when using precipitation as a predictand (Chen et al. 2012). In the case of WG approaches, the adjustment of transition probabilities, such as a wet day following a wet day $\left(P_{11}\right)$ and a wet day following a dry day $\left(P_{01}\right)$ is still a challenge. Transfer functions are the most widely used methods, with vorticity, airflow indices, wind velocity and direction, mean sea-level pressure, geopotential heights and relative humidity as the most commonly used predictors (Wilby et al. 1998b, Sailor \& Li 1999, Solman \& Nunez 1999, Trigo \& Palutikof 2001). The challenge in selecting appropriate predictors is that they must be realistically simulated by GCMs while being strongly correlated to the predictand. In many cases, several downscaling studies used more than one of these techniques (Wilby \& Wigley 1997, Schoof et al. 2010)

Over the past decade, stochastic WGs have been commonly used as downscaling tools for climate change studies (Wilks 1992, 2010, Wilby et al. 2002b,
Pruski \& Nearing 2002, Zhang et al. 2004, Qian et al. 2005, 2010, Zhang 2005, Zhang \& Liu 2005, Kilsby et al. 2007). Daily stochastic WGs like WGEN (Richardson 1981, Richardson \& Wright 1984), CLIGEN (Nicks \& Lane 1989, Nicks et al. 1995), WeaGETS (authors' unpubl. data), and LARS-WG (Semenov \& Barrow 2002) can rapidly produce climate projections at a daily time scale that can be used to quantify the impacts of climate change. These weather generators are developed based on parametric and nonparametric methods, but the parametric method is the most commonly used one. Apipattanavis et al. (2007) also presented a semi-parametric multivariate and multisite weather generator that generates precipitation states with a 3-state, first-order Markov chain and multivariate variables with a k-nearest neighbor bootstrap resampler.

There are 2 main approaches for parametric adjustments of WGs (Wilks 2010). The first involves a dayby-day change to the WG parameters based on daily variations in atmospheric circulation (Wilby et al. $2002 b)$. The other one is the most commonly used method and involves changes in WG parameters based on changes of monthly statistics projected by climate models (Qian et al. 2005, 2010, Zhang 2005, Kilsby et al. 2007, Wilks 2010). Wilby et al. (2002b) explored the use of synoptic-scale predictor variables (North Atlantic oscillation and sea surface temperature) to downscale both high- and low-frequency variability of daily precipitation at sites across Great Britain. The results showed that conditionally stochastic rainfall models displayed additive effects on monthly rainfall statistics. However, the relationship between precipitation parameters and indices was very weak for most of the tested stations. Furthermore, Schoof et al. (2010) constructed regressive models between WG parameters (precipitation parameters) and large scale predictors for developing daily precipitation projections for the United States. Again, the performance of regressive models depended on the correlations between precipitation parameters and large scale predictors.

Other work indicates that statistical downscaling using GCM precipitation directly as a predictor performed much better than using other predictors (Widmann et al. 2003, Zhang 2005). Wilks (1992) originally proposed a method modifying the daily WG parameters based on the changes of monthly averaged statistics projected by climate models. This method modified the unconditional probability of daily precipitation occurrence and a dependence parameter instead of the precipitation transition probabilities of precipitation occurrence. For the 
downscaling of mean maximum and minimum temperatures $\left(T_{\max }\right.$ and $\left.T_{\min }\right)$, changes in the mean of observations were reflected directly in the expected changes projected by GCMs. Temperatures were downscaled conditioned on wet and dry days, but the same changes were applied to the mean for wet and dry days. Zhang (2005) also presented a method for statistically downscaling GCM monthly outputs from GCM grid scale to site-specific scale using GCMprojected precipitation and temperature as predictors. GCM-projected monthly precipitation was first spatially downscaled from a grid box to a target station using transfer functions. The spatially downscaled monthly precipitation was then downscaled to daily precipitation series at the target station using CLIGEN. For the downscaling of precipitation occurrence, transition probabilities were adjusted based on spatially downscaled monthly precipitation. This method has not been tested in different climates, and the relationships between transition probabilities and monthly precipitation may depend on geographical location. A spatially downscaled monthly mean $T_{\max }$ and $T_{\min }$ were directly used in CLIGEN as the adjusted parameters for the changed climate. Adjusted daily temperature variances for each month were obtained by multiplying the observed daily temperature variances by the variance ratios between spatially downscaled monthly projections and observed monthly values.

The change factor $(\mathrm{CF})$ method is a straightforward and widely used downscaling method (Diaz-Nieto \& Wilby 2005). It establishes a baseline climatology using long-term climate data for the target site.
The changes between present and future climates derived from a GCM grid point close to the target site, usually at a monthly scale, are added to (for temperature) or multiplied by (for precipitation) each day in the baseline time series. This method is computationally straightforward and easy to apply. The most significant drawback is that the temporal sequencing of wet and dry days and the variance of temperature are unchanged. There is however a change in precipitation variance derived from the change of mean precipitation.

The objective of the present study is to present a statistical downscaling method combining the attributes of both stochastic WG and the CF methods based on the changes of monthly statistics projected by a regional climate model. This method is further compared to the CF method by quantifying the hydrological impacts of climate change for a Canadian watershed (Quebec province). The huge advantage of the developed method over the CF method is that differences in precipitation occurrence and variance of all variables can be specifically taken into account. In addition, a time series of any length can be generated: an advantage for the study of extremes.

\section{STUDY AREA AND DATA}

\subsection{Study area}

This study was conducted for the Manicouagan 5 river basin (Fig. 1) located in central Quebec, Canada. It covers $24610 \mathrm{~km}^{2}$ of mostly forested area.
Fig. 1. Location of Manicouagan 5 river basin

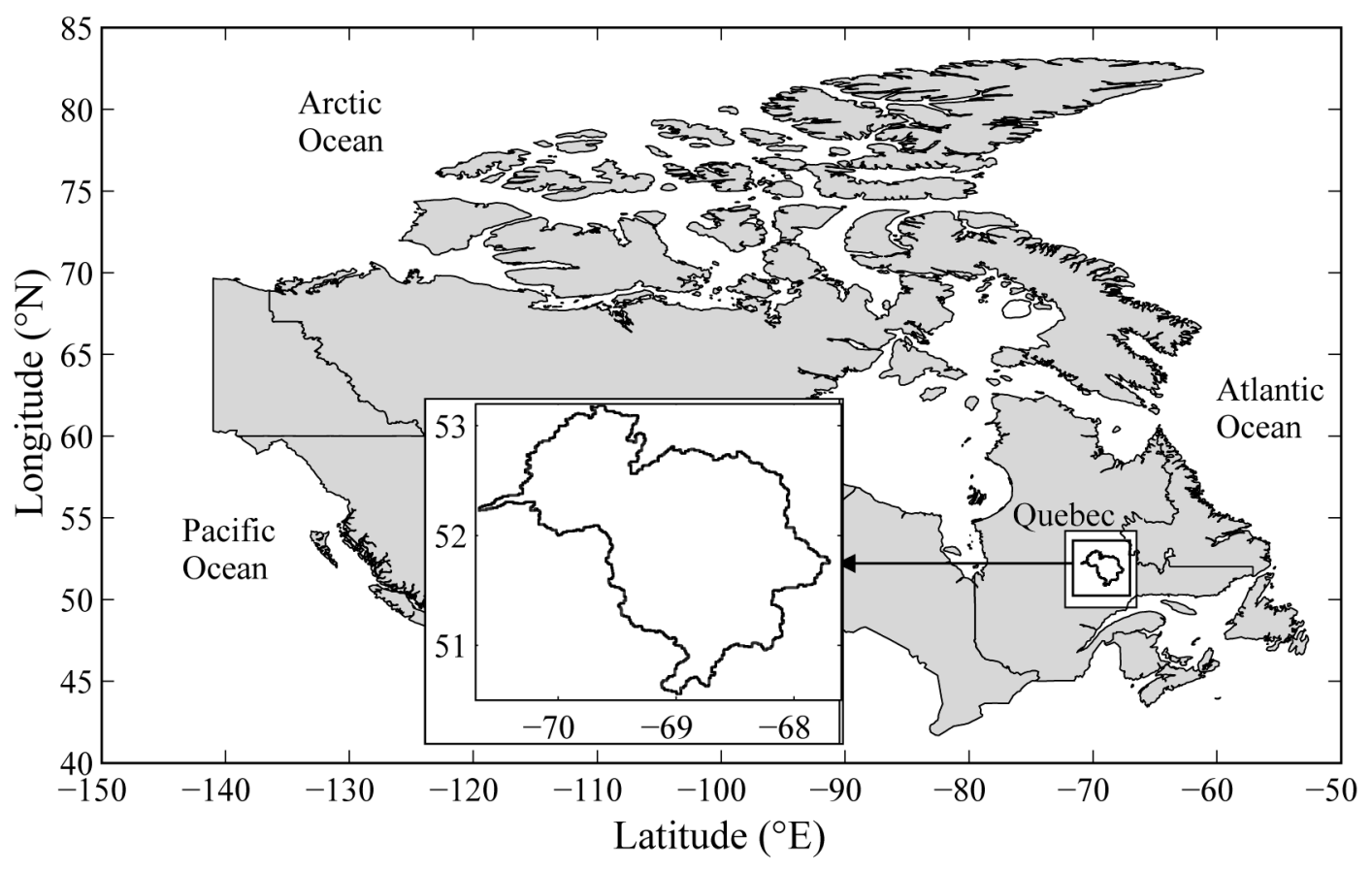


It has a rolling to moderately hilly topography with a maximum elevation of $952 \mathrm{~m}$ above sea level (a.s.1.). The reservoir at the basin outlet has a mean level of $350 \mathrm{~m}$ a.s.l. Population density is extremely low and logging is the only industrial activity over the basin. The basin drains into the Manicouagan 5 reservoir, a $2000 \mathrm{~km}^{2}$ annular reservoir within an ancient eroded impact crater. The basin ends at the Daniel Johnson dam, which is the largest buttressed multiple arch dam in the world. The installed hydropower capacity of the dam is $2.6 \mathrm{GW}$. The annual mean discharge of the Manicouagan 5 River is $529 \mathrm{~m}^{3} \mathrm{~s}^{-1}$. Snowmelt peak discharge usually occurs in May and averages $2200 \mathrm{~m}^{3} \mathrm{~s}^{-1}$.

\subsection{Data}

The observed data consisted of daily precipitation, $T_{\max }$ and $T_{\min }$ interpolated on a $10 \mathrm{~km}$ grid by the National Land and Water Information Service using 7514 weather stations over Canada (www.agr.gc.ca/ nlwis-snite). The interpolation is performed using a thin plate smoothing spline surface fitting method (Hutchinson et al. 2009). All grid daily precipitation, $T_{\max }$ and $T_{\min }$ are averaged over the river basin. Discharge data at the basin outlet was obtained from mass balance calculations at the dam and provided by Hydro-Québec. Climate data consisted of RCMprojected daily precipitation, $T_{\max }$ and $T_{\min }$. Data from the Canadian RCM (CRCM v.4.2.0; Music \& Caya 2007, 2009) with a grid resolution of $45 \mathrm{~km}$ driven by the Canadian GCM (CGCM3 v3.1; DAI CGCM3 Predictors 2008) under the IPCC A2 gas emission scenario. The CRCM grid data are also averaged over the river basin to match the observed data. This work covers the 1970-1999 period (reference period) for calibration and the 2011-2099 period in climate change mode. For the 2011-2099 climate data, 30-yr moving averages were calculated, which resulted in sixty 30 yr horizons centered over 2025 to 2084 .

\section{METHODOLOGY}

A downscaling method based on WG is presented below. Precipitation, $T_{\max }$ and $T_{\min }$ were downscaled from the CRCM scale to the site-specific scale (basin average of $10 \mathrm{~km}$ grid) over the 2025-2084 period (centered by 30 yr moving averages from 2011 to 2099). The precipitation threshold used to discriminate between wet and dry days is $0.5 \mathrm{~mm}$. If daily precipitation is $\geq 0.5 \mathrm{~mm}$, this given day is defined as being wet. The choice of a different threshold has been investigated and shown not to influence the results. The results were compared against the widely-used CF method in downscaling precipitation, $T_{\max }$ and $T_{\min }$ and in simulating hydrological impacts using a lumped conceptual hydrological model.

\subsection{Downscaling of weather generator parameters}

The WG used in this research is CLIGEN (Nicks \& Lane 1989). In this study, only the functions to generate precipitation (occurrence and quantity), $T_{\max }$ and $T_{\min }$ were used. For convenience, CLIGEN was chosen in spite of generating precipitation and temperature independently, and the mean and standard deviation of each variable are explicitly used in its probability distribution function, so that the incorporation of GCM projected monthly changes in statistical moments is straightforward (Zhang 2005, Chen et al. 2009). However, other WGs could also have been used.

In CLIGEN, a first-order two-state Markov chain is used to generate the occurrence of wet or dry days. The probability of precipitation on a given day is based on the wet or dry status of the previous day, which can be defined in terms of the 2 transition probabilities: $P_{01}$ and $P_{11}$. For a predicted wet day, a 3-parameter skewed normal Pearson III distribution was used to generate daily precipitation quantity for each month (Nicks \& Lane 1989). A normal distribution was used to simulate $T_{\max }$ and $T_{\min }$. The temperature with the smaller standard deviation between $T_{\max }$ and $T_{\min }$ is computed first, followed by the other temperature. This preserves the cross-correlation between $T_{\max }$ and $T_{\min }$ (Chen et al. 2008). To capture their autocorrelation, 2 random numbers are used to obtain the standard normal deviate; the second number for one day is reused as the first number for the next day (Zhang 2004). The mean and standard deviation of $T_{\max }$ and $T_{\min }$ were calculated monthly and smoothed with a Fourier interpolation scheme to the daily scale.

A total of 9 monthly parameters are needed by CLIGEN to generate precipitation, $T_{\max }$ and $T_{\min }$. These include $P_{01}$ and $P_{11}$ for generating precipitation occurrence, the mean, standard deviation and skewness for generating daily precipitation quantity and the means and standard deviations for generating $T_{\max }$ and $T_{\min }$.

A method is presented to modify the above mentioned parameters based on the changes of precipi- 
tation, $T_{\max }$ and $T_{\min }$ projected by the CRCM. This method could also be used with GCM outputs. Based on the work of Wilks (1992), the daily WG parameters were modified according to the changes of monthly averaged statistics projected by climate models. For downscaling of precipitation occurrence, Wilks (1992) modified the unconditional probability of daily precipitation occurrence $(\pi)$ and a dependence parameter $(r)$ rather than acting directly on the transition probabilities of precipita- tion occurrence $\left(P_{11}\right.$ and $\left.P_{01}\right)$. However, the changes of $P_{11}$ and $P_{01}$ are more gradual and less noisy than those of $\pi$ and $r$ for both CGCM and CRCM projected daily precipitation (Fig. 2). The correlations between 30-yr moving averages of CGCM3- and CRCM-simulated seasonal $P_{11}$ (and $P_{01}$ ) and their linear regressions are also consistently stronger than those between $r$ and their linear regressions for all 4 seasons (Table 1). Thus, the proposed method directly modifies the transition probabilities of pre-
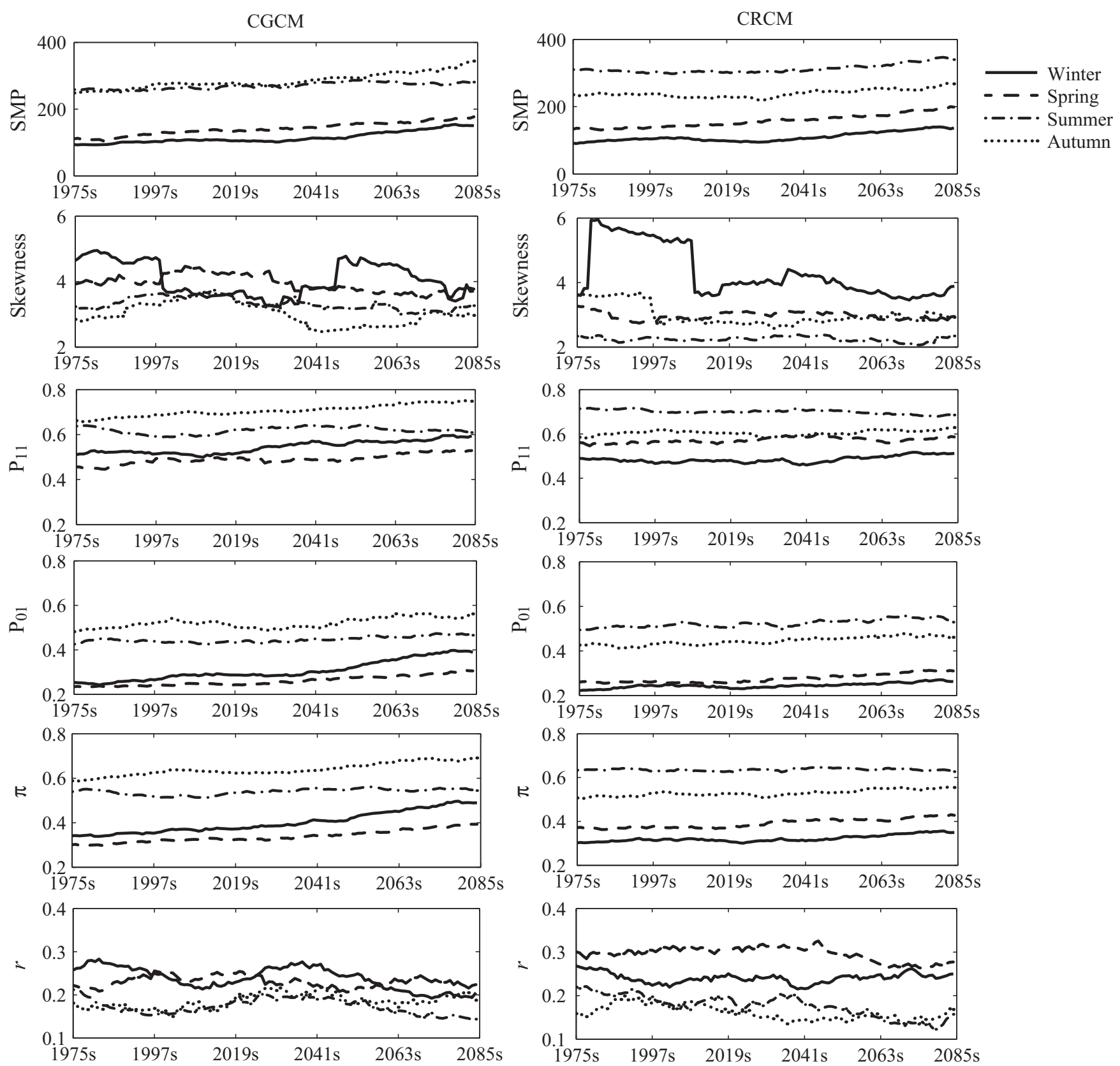

Fig. 2. The 30-yr moving averages of seasonal mean precipitation (SMP), skewness of daily precipitation distribution (Skewness), conditional $\left(\mathrm{P}_{01}, \mathrm{P}_{11}\right)$ and unconditional $(\pi)$ probability of precipitation occurrence, and dependence parameter $(r)$ for CRCM and CGCM data over the 1961-2099 period 
Table 1. Correlation coefficient $\left(\mathrm{R}^{2}\right)$ of the linear regression for the Canadian Regional Climate (CRCM) and General Circulation (CGCM) Models statistics, including seasonal mean precipitation (SMP), skewness of daily precipitation distribution (Skewness), conditional $\left(\mathrm{P}_{01}, \mathrm{P}_{11}\right)$ and unconditional $(\pi)$ probability of daily precipitation occurrence and dependence parameters $(r)$ for $2025-2084$

\begin{tabular}{|c|c|c|c|c|c|c|c|c|c|c|c|c|}
\hline & \multicolumn{6}{|c|}{ CGCM } & \multicolumn{6}{|c|}{ CRCM } \\
\hline & SMP & Skewness & $\mathrm{P}_{01}$ & $\mathrm{P}_{11}$ & $\pi$ & $r$ & SMP & Skewness & $\mathrm{P}_{01}$ & $\mathrm{P}_{11}$ & $\pi$ & $r$ \\
\hline Winter & 0.83 & 0.08 & 0.89 & 0.80 & 0.94 & 0.45 & 0.7 & 0.53 & 0.62 & 0.43 & 0.67 & 0.002 \\
\hline Spring & 0.97 & 0.48 & 0.92 & 0.81 & 0.94 & 0.04 & 0.96 & 0.03 & 0.87 & 0.50 & 0.88 & 0.34 \\
\hline Summer & 0.73 & 0.33 & 0.61 & 0.46 & 0.37 & 0.10 & 0.62 & 0.05 & 0.76 & 0.59 & 0.03 & 0.77 \\
\hline Autumn & 0.89 & 0.20 & 0.53 & 0.95 & 0.87 & 0.28 & 0.50 & 0.29 & 0.83 & 0.38 & 0.72 & 0.48 \\
\hline
\end{tabular}

cipitation occurrence $\left(P_{11}\right.$ and $\left.P_{01}\right)$. The parameters of WG were modified to take into account variations projected by a climate model (GCM or RCM). This variation is based on a delta change approach. For example, take the probability of occurrence of $P_{01}$, a common parameter of WG using a two-state Markov chain for precipitation occurrence. Since the spatial resolution of GCM or RCM is of the order of 100 s or 10 s of $\mathrm{km}, P_{01}$ from GCM or RCM data will not match the $P_{01}$ measured at a station. Thus, similarly to the CF method, the difference between $P_{01}$ projected by GCM (or RCM) in present and future climate will be applied to the observed data. The same method was also applied to the probability of occurrence of $P_{11}$ and the monthly mean precipitation (MMP). The skewness of daily precipitation distribution does not change gradually, but displays large fluctuations, especially for the winter precipitation (Fig. 2). This is not surprising since the skewness is largely influenced by extreme precipitations that are not well represented by climate models. Thus, a simple modification of the changes in skewness projected by climate models between future and reference periods may result in unacceptable biases. To simplify the process, the skewness of the precipitation distribution was presumed to be unchanged in the future for this study. Accordingly, 8 parameters required modification for every climate change scenario.

Details of parameter modifications follow the following steps: (1) Similarly to the CF method, the adjusted monthly mean $T_{\max }$ and $T_{\min }$ for the future horizon $\left(\bar{T}_{a d j, f u t}\right)$ were estimated as (Chen et al. 2011):

$$
\bar{T}_{\text {adj,fut }}=\bar{T}_{\text {obs }}+\left(\bar{T}_{C M, \text { fut }}-\bar{T}_{C M, \text { ref }}\right)
$$

The adjusted values were obtained by adding the differences predicted by a GCM or an RCM between the future (fut) horizon and the reference (ref) period $\left(\bar{T}_{C M, f u t}-\bar{T}_{C M, r e f}\right)$ to the observed mean monthly observed temperatures $\left(\bar{T}_{o b s}\right)$.
(2) Monthly means and variances of precipitation, monthly variances of $T_{\max }$ and $T_{\min }$ and the transition probabilities of precipitation occurrence $P_{01}$ and $P_{11}$ for the future horizon were adjusted by:

$$
X_{a d j, f u t}=X_{o b s} \times\left(X_{C M, f u t} / X_{C M, r e f}\right)
$$

where $X$ represents the variable to be adjusted. The subscripts were the same as above.

(3) The $P_{01}$ and $P_{11}$ values are expressed in terms of $r$ for further adjustments, as:

$$
\begin{gathered}
\pi=\frac{P_{01}}{1+P_{01}-P_{11}} \\
r=P_{11}-P_{01}
\end{gathered}
$$

(4) The adjusted mean daily precipitation per wet day $\left(\mu_{\mathrm{d}}\right)$ was estimated (as Wilks 1992, 1999, Zhang 2005):

$$
\mu_{d}=\frac{\mu_{m}}{N_{d} \pi}
$$

where $N_{d}$ is the number of days in a month, $N_{d} \pi$ is the average number of wet days in a month, and $\mu_{\mathrm{m}}$ is the step (2)-adjusted monthly precipitation.

(5) The adjusted daily variance $\left(\sigma_{d}^{2}\right)$ was approximated using Eq. (6), based on the step (2)-adjusted variance of the monthly precipitation $\left(\sigma_{m}^{2}\right)$ (Wilks 1992, 1999).

$$
\sigma_{d}^{2}=\frac{\sigma_{m}^{2}}{N_{d} \pi}-\frac{(1-\pi)(1+r)}{1-r} \mu_{d}^{2}
$$

All adjusted precipitation, $T_{\max }$ and $T_{\min }$ parameter values are input into CLIGEN to generate $900 \mathrm{yr}$ long time series of daily meteorological data. Long time series are used to obtain the true expectancy of a WG. Short time series could result in biases due to the random nature of the stochastic process. Each $900 \mathrm{yr}$ time series is representative of a $30 \mathrm{yr}$ horizon as defined earlier. All in all, sixty 900 yr time series (centered over 2025 to 2084) were generated. The flow chart of WG-based downscaling is presented in Fig. 3. 


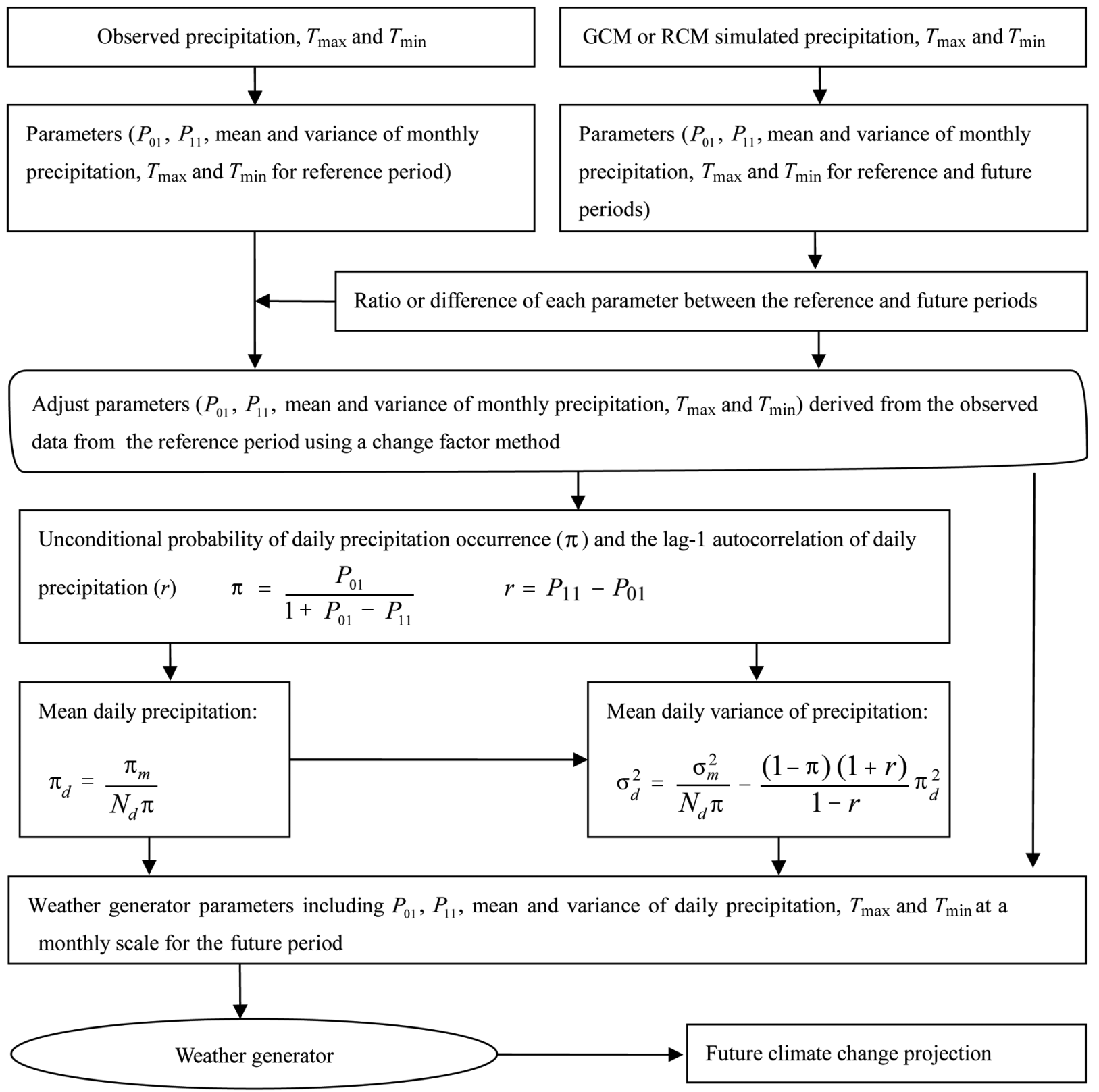

Fig. 3. Flow chart of downscaling of weather generator parameters

\subsection{Change factor method}

The CF method involves adjusting the observed daily temperature $\left(T_{o b s, d}\right)$ by adding the difference in monthly temperature between the future horizon and the reference period predicted by the climate model (GCM or RCM) $\left(\bar{T}_{C M, f u t, m}-\bar{T}_{C M, r e f, m}\right)$ to obtain the daily temperature at the future horizon $\left(T_{\text {adj,fut,d }}\right)$ (Chen et al. 2011):

$$
T_{a d j, f u t, d}=T_{o b s, d}+\left(\bar{T}_{C M, f u t, m}-\bar{T}_{C M, r e f, m}\right)
$$

The adjusted daily precipitation for the future horizon $\left(P_{a d j, f u t, d}\right)$ was obtained by multiplying the precipitation ratio $\left(\bar{P}_{C M, f u t, m} / \bar{P}_{C M, r e f, m}\right)$ by the observed daily precipitation $\left(P_{o b s, d}\right)$ :

$$
P_{a d j, f u t, d}=P_{o b s, d} \times\left(\bar{P}_{C M, f u t, m} / \bar{P}_{C M, r e f, m}\right)
$$

\subsection{Hydrological simulation}

The hydrological simulation used the HASMI hydrological model developed by Hydro-Québec, 
which has been used to forecast natural inflows for over 20 yr (Fortin 2000). HSAMI is used by HydroQuébec for hourly and daily forecasting of natural inflows over 84 watersheds with surface areas ranging from 160 to $69195 \mathrm{~km}^{2}$. HSAMI is a 23-parameter, lumped, conceptual, rainfall-runoff model. Two parameters account for evapotranspiration, 6 for snowmelt, 10 for vertical water movement, and 5 for horizontal water movement. Vertical flows are simulated with 4 interconnected linear reservoirs (snow on the ground, surface water, unsaturated and saturated zones). Horizontal flows are filtered through 2 hydrograms and 1 linear reservoir. Model calibration is done automatically using the shuffled complex evolution optimization algorithm (Duan 2003). The model takes snow accumulation, snowmelt, soil freezing/thawing and evapotranspiration into account.

The basin-averaged minimum required daily input data for HSAMI are $T_{\max }, T_{\min }$ and liquid and solid precipitations. The liquid and solid precipitations are partitioned based on the mean temperature. If the mean temperature is $\geq 2^{\circ} \mathrm{C}$, all precipitation is rainfall, if the mean temperature is $\leq-2^{\circ} \mathrm{C}$, all precipitation is solid. Otherwise, precipitation is linearly partitioned between snow and rainfall. Cloud cover fraction and snow water equivalent can also be used as inputs, if available. A natural inflow or discharge time series is also needed for proper calibration/validation. For this study, 30 yr (1970 to 1999) of daily discharge data were used for model calibration/validation. The optimal combination of parameters was selected based on Nash-Sutcliffe criteria (Duan et al. 1994, Duan 2003). The set of parameters thus chosen yielded Nash-Sutcliffe criteria values of 0.89 for both the validation $(20 \mathrm{yr})$ and calibration $(10 \mathrm{yr})$ periods. This high Nash-Sutcliffe criteria value is representative of the good quality of the weather inputs, observed discharge values and hydrological model.

\section{RESULTS}

\subsection{Validation of the weather generator and the hydrological model}

The validation of the hydrological model HSAMI was based on the performance of the simulated hydrographs (using the hydrology model driven by the observed meteorological data, labeled SIM) at the basin outlet compared to the observed hydrograph. The 10th, 50th and 90th percentiles of annual hydrographs are presented in Fig. 4. Annual hydrographs simulated by HSAMI using CLIGENgenerated data (labeled WG) using the observed monthly statistics for the reference period are also displayed to validate the ability of CLIGEN at generating weather data representative of its training period. Annual hydrographs from the observed discharge (labeled OBS) are also presented for comparison. The observed precipitation and temperatures resulted in hydrographs that are very close to observed ones. Additionally, precipitation and temperatures obtained from the weather generator are able to reproduce the interannual variability of streamflow. Even though slight biases were introduced by CLIGEN and HSAMI, the overall fits are quite good.

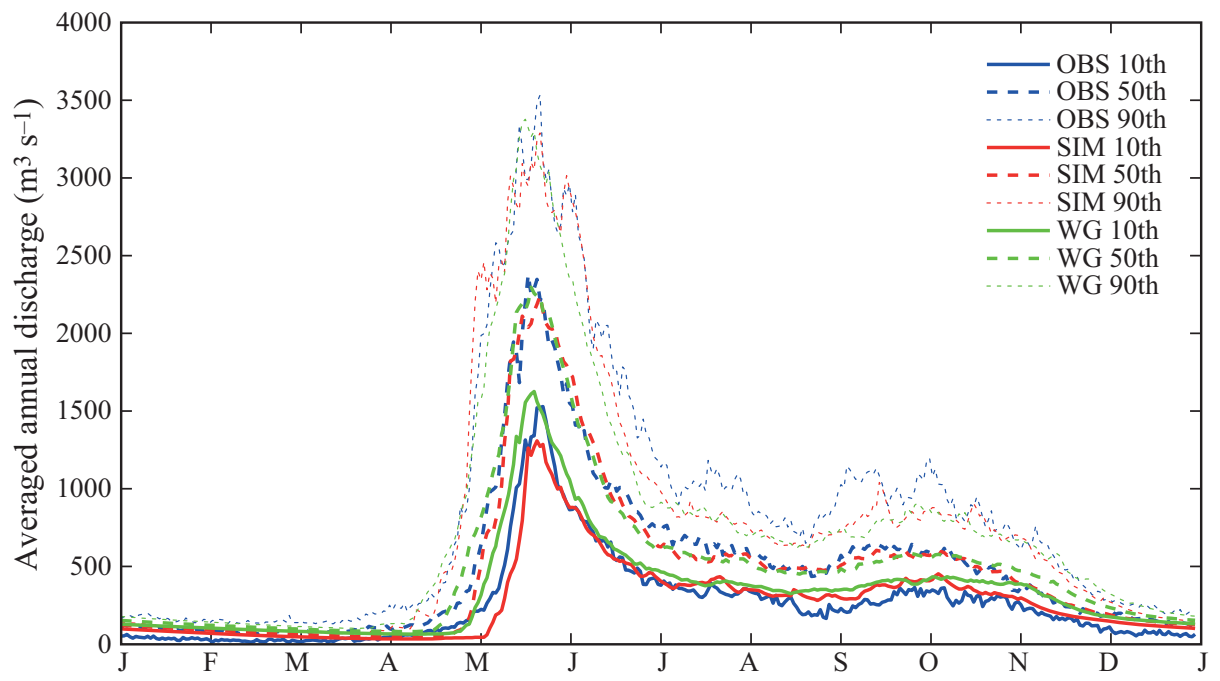

Fig. 4. Tenth, 50th and 90th percentiles of observed (OBS) and HSAMI simulated (SIM) hydrographs (mean annual discharge) for the reference period (1970-1999) at the Manicouagan 5 watershed. HSAMI-simulated hydrographs using CLIGENproduced meteorological data at the reference period (WG) are also plotted 


\section{2. Climate change projections}

\subsubsection{Dry and wet day spells}

The CF method does not take into account the temporal sequencing of dry and wet days, which is its main drawback. The WG-based method modifies the transition probabilities of precipitation occurrence based on RCM-projected variations. Thus, the dry and wet day spells change according to the differences in RCM-projected dry and wet day spells between the future and reference periods. Fig. 5 shows the average dry and wet day spells downscaled by the CF and WG-based methods, respectively, for 12 mo over the 2025-2084 period (30 yr moving average from 2011 to 2099) for the Manicouagan 5 river basin. Changes in precipitation occurrence are not taken into account by the $\mathrm{CF}$ method. Thus, the average dry and wet day spells are stationary over the 2025-2084 period for all months (horizontal dashed lines in Fig. 5) and are similar to those from the reference period. The WG-based method displays clear trends throughout the century, which is markedly different from the situation at the reference period. The WG-based method suggested shorter dry day spells for all months of the 2025-2084 period compared to those of the reference period, indicating that wet days will become more common. However, there is no uniform pattern for monthly average wet day spells, which are predicted to be longer for April and November and shorter for July and August for the 2025-2084 period. In addition, this pattern would be first shorter and then longer than that of the reference period for January, March, September, October and December throughout the 2025-2084 period. In contrast, February wet day spells would have an opposite trend to that of the reference period.

\subsubsection{Mean and standard deviation of daily precipitation}

Both the CF and WG-based methods specifically take into account the changes of monthly precipitations projected by RCM; thus, they suggest similar increases in annual and seasonal precipitations for
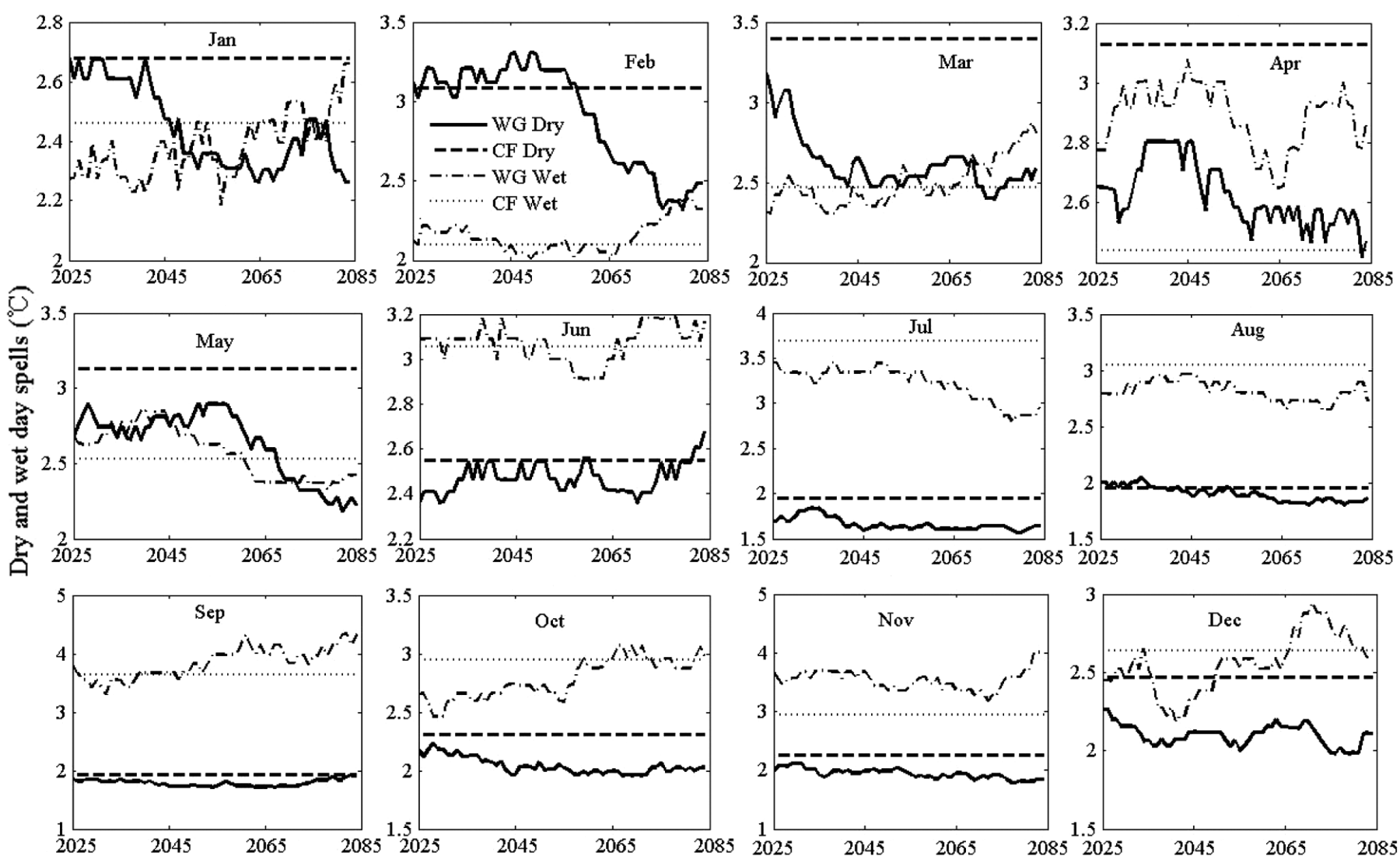

Fig. 5. Mean dry and wet day spells downscaled by change factor (CF) and weather generator-based (WG) methods for each month of 2025-2084 for the Manicouagan 5 river basin 
the 2025-2084 period (results not shown). But, as mentioned earlier, the dry and wet day spells are significantly different. Specifically, mean daily precipitation changes in the opposite direction to that of the wet day frequency. Fig. 6 demonstrates the mean and standard deviation of daily precipitation downscaled by the 2 methods for 12 mo over the 20252084 period. Both downscaling methods show gradual increases in mean daily precipitation for all months in this period. However, the CF method suggests more increases in mean daily precipitation than the WG-based method. This is because the WGbased method predicts more wet days with similar annual and seasonal precipitations than the $\mathrm{CF}$ method.

Both CF and WG-based methods suggest changes in daily precipitation variance. The change of variance predicted by the CF method is based on the change of mean daily precipitation, because the CF method does not specifically modify the precipitation variance. However, the WG-based method specifically takes into account the variance of precipitation based on RCM-projected variations. Both downscaling methods suggest general in- creases in the standard deviations of daily precipitation for all months (Fig. 6). For the CF method, the change in standard deviation of daily precipitation is consistent with the change in the mean precipitation. The WG-based method suggests more future variability, consistent with that predicted by the RCM.

\subsubsection{Standard deviation of daily $T_{\max }$ and $T_{\min }$}

The CF method does not take into account the change of variance for $T_{\max }$ and $T_{\min }$. Standard deviations of $T_{\max }$ and $T_{\min }$ downscaled by the CF method are constant for the 2025-2084 period, which is exactly equal to that of the reference period as presented in Fig. 7. However, similarly to the transition probabilities of precipitation occurrence, the WGbased method adjusts the variances of $T_{\max }$ and $T_{\min }$ based on the RCM-projected changes. Compared to the reference period (1970-1999), the WG-based method suggests decreases in the variability of winter (December, January and February) $T_{\max }$, while it suggests increases for all other months.
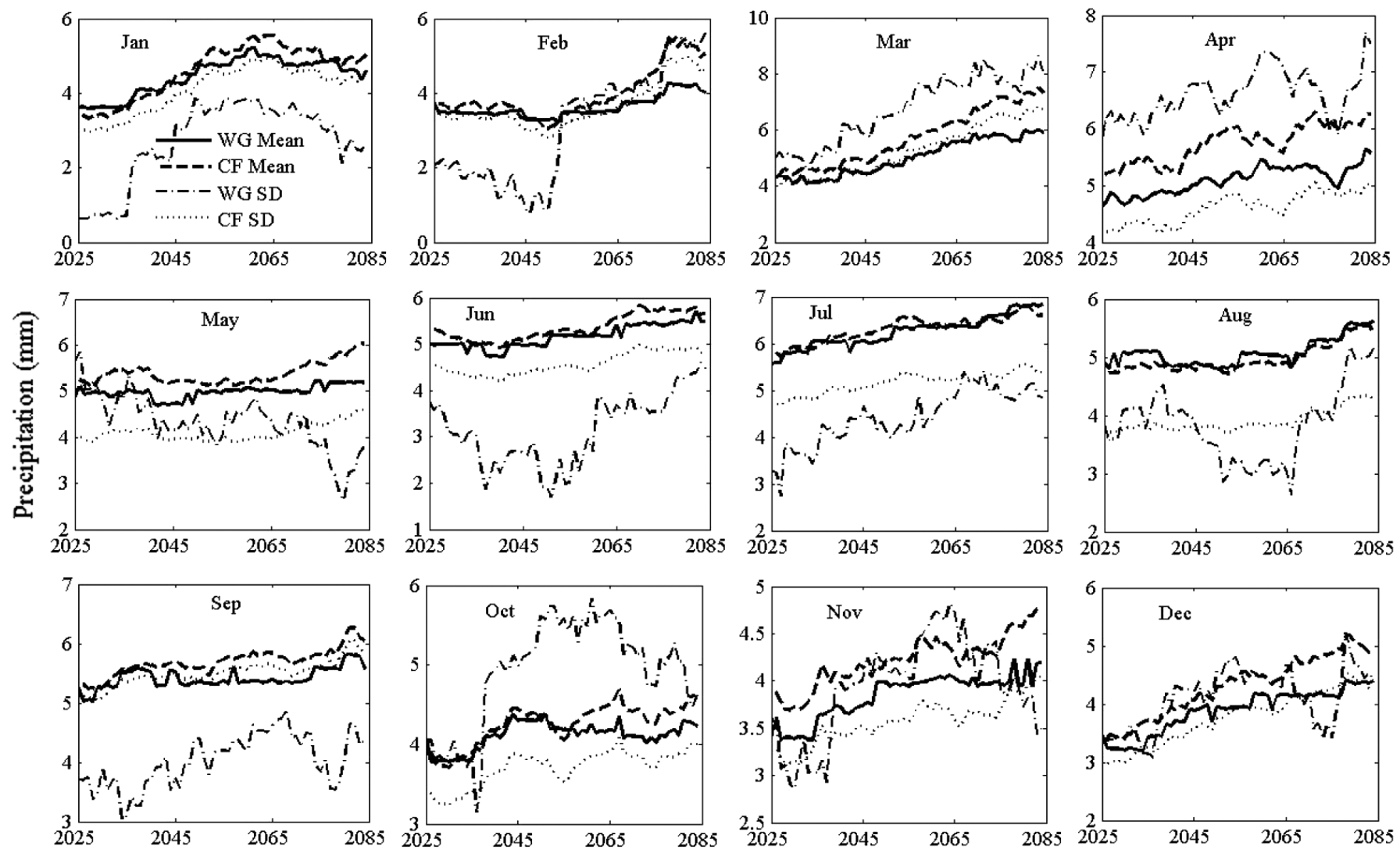

Fig. 6. Mean and standard deviation (SD) of daily precipitation downscaled by change factor (CF) and weather generatorbased (WG) methods for each month of 2025-2084 for the Manicouagan 5 river basin 

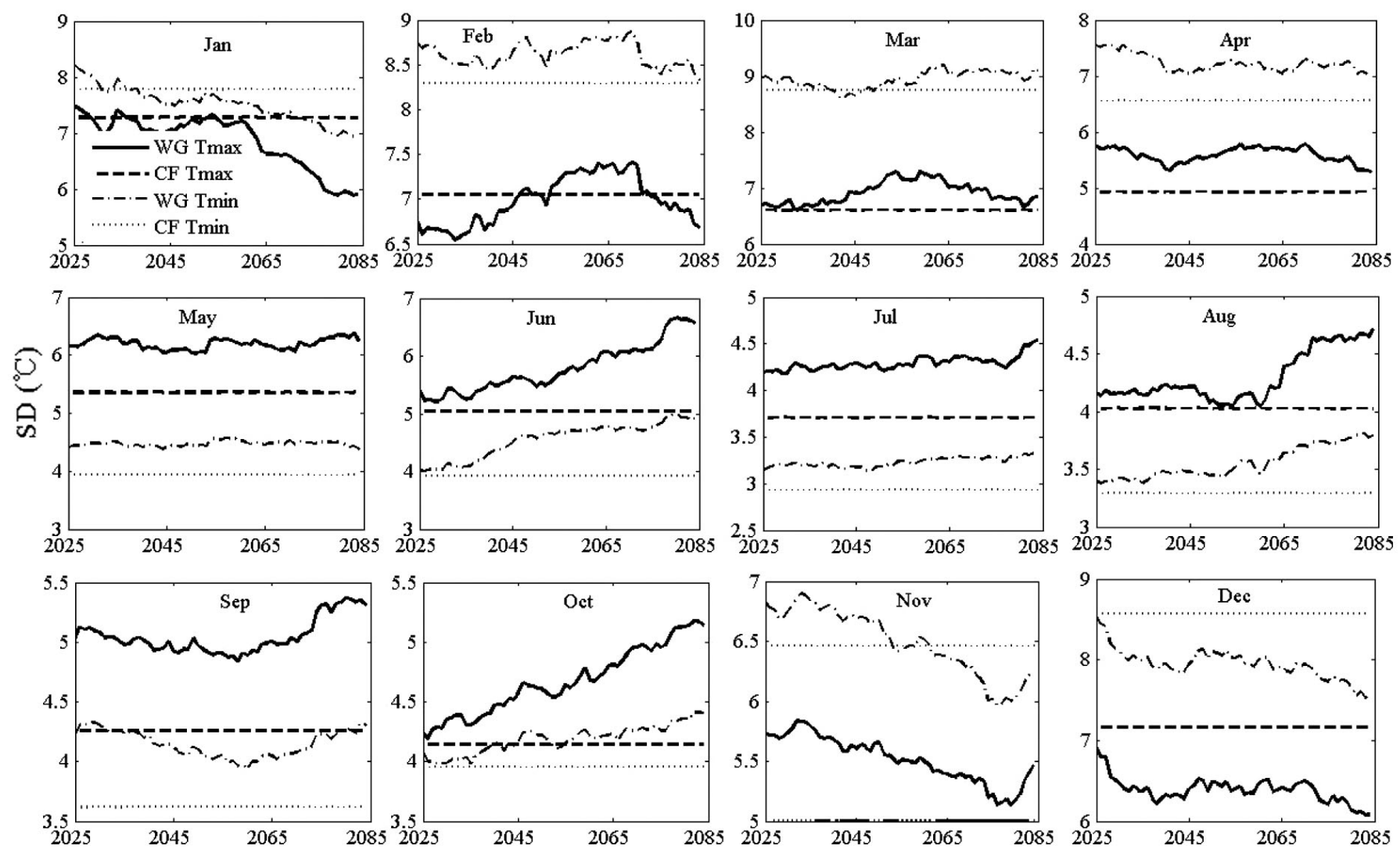

Fig. 7. Daily standard deviation (SD) of $T_{\max }$ and $T_{\min }$ downscaled by change factor (CF) and weather generator-based (WG) methods for each month of 2025-2084 for the Manicouagan 5 river basin

\subsection{Hydrological impacts}

\subsubsection{Annual hydrograph}

Fig. 8 presents the envelope of the annual hydrographs simulated with the weather variables downscaled by the CF and WG-based methods. Each envelope is represented by 60 annual hydrographs (2025-2084 period). When the time period is near the reference period, the annual hydrograph of the future period is close to that of the reference period. To avoid the minor bias resulting from the hydrological model when comparing the future to the reference period, the discharge at the reference period is represented by model data and not by the observed discharge. The results showed that both downscaling methods suggest increases in winter (Nov-Apr) discharge. Decreases in summer (JunOct) are predicted for most future horizons, especially for those downscaled by the WG-based method. The WG-based method suggests peak discharges higher than both those of the CF method and the simulated peak discharges at the reference period. Significantly, the peak discharges increase even more as the future advances. Peak discharges over the 2025-2085 period are predicted to be earlier than those at the reference period by both downscaling methods. Lags vary from $12 \mathrm{~d}$ (May 12) to $19 \mathrm{~d}$ (May 5) for the WG-based method and from 6 (May 18) to $22 \mathrm{~d}$ (May 2) for the CF method.

\subsubsection{Annual and seasonal discharges}

Fig. 9 presents the 30 yr moving averages of annual and seasonal discharges simulated by HSAMI using weather data downscaled by the CF and WG-based methods. Compared to the reference period discharge (straight dashed line in Fig. 9), both methods suggest increases in annual, spring and winter discharges over the 2025-2084 period. The CF method predicts decreases in summer-autumn discharge for most horizons, whereas the change is more gradual with the WG approach. Even though both downscaling methods predict similar annual and seasonal mean precipitations and temperatures, the annual and seasonal discharges are different, especially for seasonal discharge. This indicates that the annual 

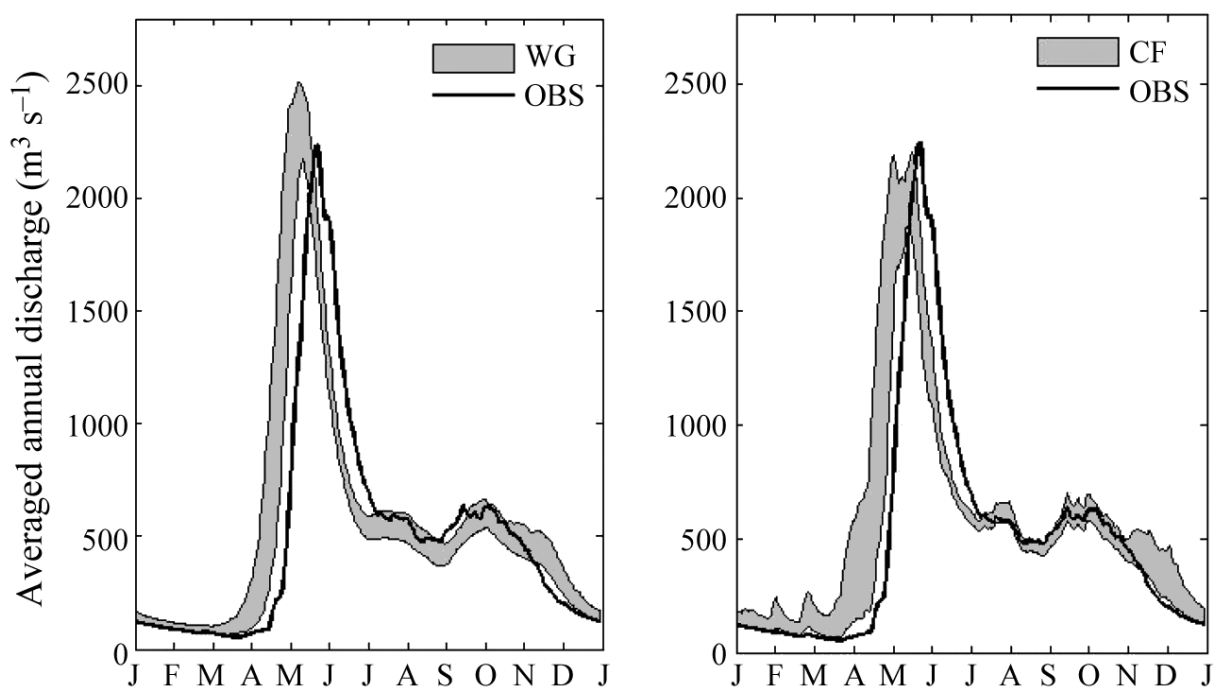

Fig. 8. Envelopes of 60 annual hydrographs simulated with precipitation, $T_{\max }$ and $T_{\min }$ values downscaled using change factor (CF) and weather generator-based (WG) methods over the 2025-2084 period at the Manicouagan 5 river basin. The observed hydrograph (OBS) for 1970-1999 is displayed for comparison

and seasonal discharges are not only affected by the means of the precipitation and temperatures, but also by their variances and precipitation occurrences. In addition, these results reflect that the process from climate projections to hydrologic variables is nonlinear. Annual discharge suggested by the CF method is slightly more than that predicted by the
WG-based method over the 2025-2085 period. The discharges differ more at the seasonal scale than at the annual scale. Compared to the CF method, the WG-based method suggests larger increases in spring (Apr-Jun) discharge, and smaller increases in summer-autumn (Jul-Nov) and winter (Dec-Mar) discharges.
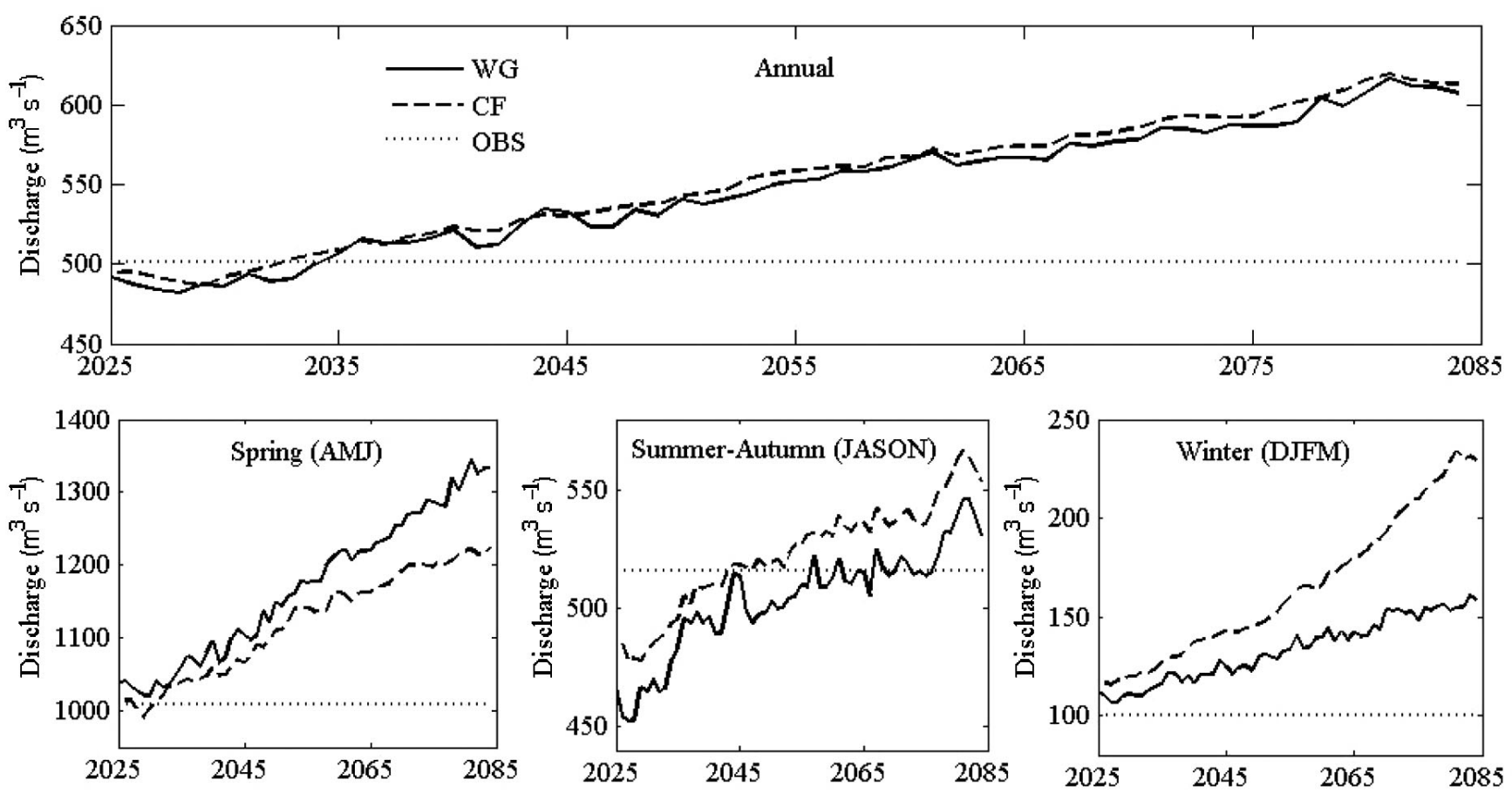

Fig. 9. Annual and seasonal mean discharge simulated with precipitation, $T_{\max }$ and $T_{\min }$ values downscaled using change factor (CF) and weather generator-based (WG) methods for 2025-2084 at the Manicouagan 5 river basin. OBS: annual and seasonal mean discharge over the reference period (1970-1999), shown for comparison 


\subsubsection{Annual and seasonal low flows}

Changes in monthly precipitation averages can conceal subtle variations in dry spells that are potentially significant for low flows (Diaz-Nieto \& Wilby 2005). The 2 downscaling methods suggest similar changes in monthly precipitation, but different changes in precipitation occurrence, resulting in noticeable differences in mean low flows at the river basin. Fig. 10 presents the $30 \mathrm{yr}$ moving averages of mean annual and seasonal low flows for the 20252084 period. Both downscaling methods suggest general increases in average annual and seasonal low flows, but there are considerable differences in their predictions. The CF method predicts larger increases in mean annual low flow than the WGbased method. These greater increases, compared to the WG-based method, occur in spring and winter low flows, resulting in the larger increases in annual low flow.

Fig. 11 presents the $30 \mathrm{yr}$ moving averages of the annual and seasonal minimal low flows for the 2025-2084 and the reference periods. Similarly to the mean low flows shown in Fig. 10, both downscaling methods suggest increases in annual and seasonal minimal low flows, but those predicted by WG-based figures display more variability. The WG method has a much longer time series (900 yr compared to $30 \mathrm{yr}$ ) that is better at sampling climate variability. The $\mathrm{CF}$ method predicts larger increases in minimal low flow, especially for the more distant future period, and larger increases in spring and winter minimal low flows than the WG-based method. The WGbased method is better able to capture long series of dry days that lead to low flows. The WG-predicted summer-autumn minimal low flows for the 20252084 period are considerably larger than those for the reference period. Both methods give similar results, although the WG-based method predicts low flows that are $10 \%$ smaller than those of the $\mathrm{CF}$ method, on average.

\section{DISCUSSIONS AND CONCLUSIONS}

A statistical downscaling method combining a stochastic WG and some aspects of the CF method was presented in this paper. The parameters of the WG were perturbed to take into account the relative variations in the means and variances of weather variables projected by a climate model. The precipitation and temperature parameters projected by climate models display gradual (significantly non-stationary) changing patterns, which form the basis for the parameter perturbation of the WG. This downscaling method is relatively simple to use and negates the
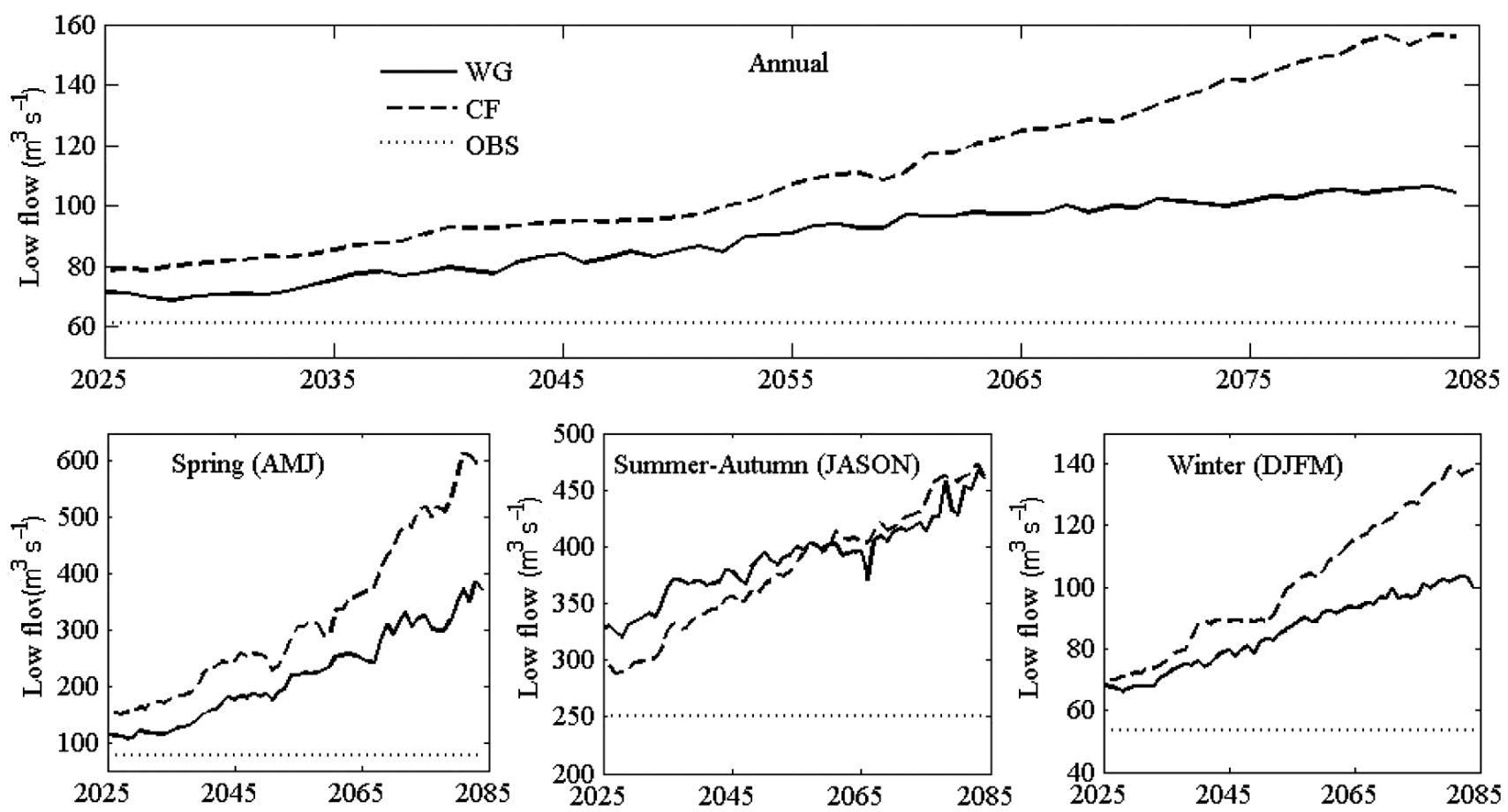

Fig. 10. Annual and seasonal mean low flow simulated with precipitation values downscaled using change factor (CF) and weather generator-based (WG) methods, $T_{\max }$ and $T_{\min }$ for 2025-2084 at the Manicouagan 5 river basin. OBS: annual and seasonal low flow for the reference period (1970-1999; OBS) 

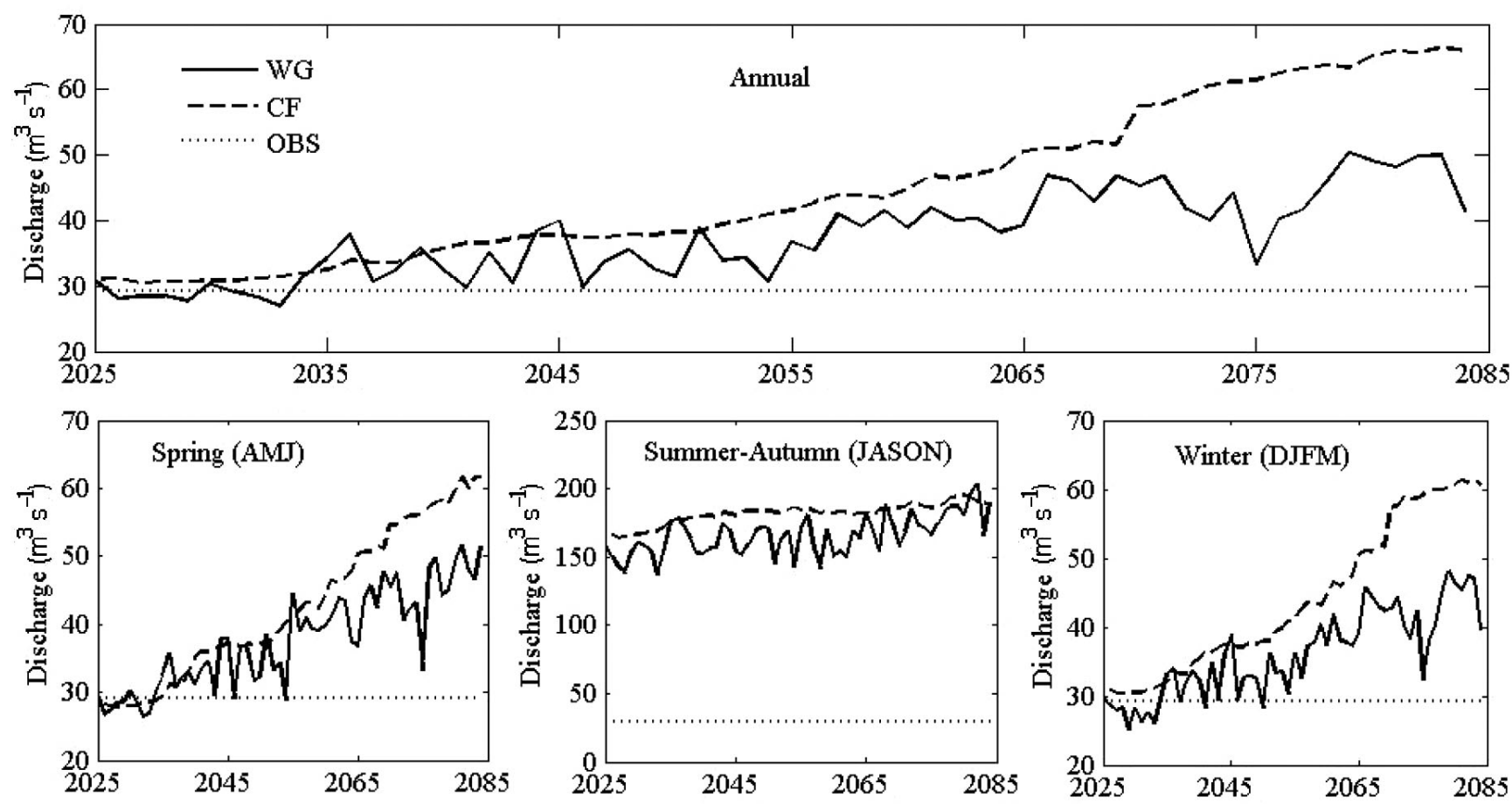

Fig. 11. Minimal annual and seasonal low flow (Q5) simulated with the change factor (CF) and weather generator-based (WG) downscaling methods for 2025-2084 at the Manicouagan 5 river basin. OBS: data for the reference period (1970-1999

prerequisite of a strong relationship between localscale variables (predictants) and large scale climate model variables (predictors) common to most statistical downscaling methods.

The proposed downscaling method was compared to the CF method in downscaling precipitation, $T_{\max }$ and $T_{\min }$ and further quantifying the hydrological impacts of climate change over the 2025-2084 period for the Manicouagan 5 river basin. Both downscaling methods suggest similar increases in annual and seasonal precipitations and temperatures for the 2025-2084 period (results not shown). This was as expected, since both approaches are similar with respect to their treatment of precipitation and temperature means. Analysis of climate change scenarios shows that monthly dry and wet spells for the 2025-2084 period predicted by the WG-based method would be considerably different from those of the reference period. The CF method does not consider any change in precipitation occurrence over the reference period, a clear weakness of the approach. Compared to the reference period, the WG-based method predicted shorter dry day spells for the 2025-2084 period, thus indicating an increasing wet day frequency. Different dry and wet day spells and similar seasonal precipitation result in different mean daily precipitations between the 2 downscaling approaches. The standard deviation of daily precipi- tation, $T_{\max }$ and $T_{\min }$ differs markedly depending on the downscaling method. This should not be a surprise, since the WG-based method specifically takes the variance change of precipitation and temperatures into account, while the CF method does not. To evaluate how those changes translated into hydrological variables, weather variables derived from both downscaling methods were fed into the lumped semi-conceptual hydrology model HSAMI.

Both downscaling methods suggest general increases in winter (Nov-Apr) discharge and decreases in summer (Jun-Oct), the increases being larger when downscaled by the WG-based method. The WG-based method suggest higher peak discharges than those predicted by the CF method and those of the reference period. Peak discharges over the 2025-2084 period would be observed earlier than those at the reference period according to both downscaling methods. The differences between the weather variables downscaled from the 2 methods are amplified when transferred to hydrologic variables. Even though both downscaling methods suggest similar increases in annual and seasonal precipitations and temperatures, the annual and seasonal discharges are markedly different, especially for seasonal discharge. This indicates that precipitation and temperature variability play an important role in the processes leading to runoff. 
The comparison of the 2 downscaling methods reveals the main weakness of the $\mathrm{CF}$ method: that it keeps the precipitation occurrence and variability of all weather variables constant. This fallibility is probably not a major obstacle with respect to spring snowmelt, as shown in Fig 9, because spring floods are the result of several months of snow accumulation followed by rapid melting. As such, the most important feature to have in a climate change study is the correct total quantity of solid precipitation. The variability of solid precipitation during the winter months is likely a less important feature, unless variability adds the frequent mid-winter thaws that cannot be captured by the CF method. For summer and fall events, climatic disasters often result from one major rainfall event, or from droughts that occur after long periods with little to no precipitation. In such cases, the CF method would be totally inappropriate for climate change studies. This situation is clearly delineated by the low flow results, where the 2 downscaling approaches display very different trends. The proposed WG-based method takes into account the change of precipitation occurrence and the variance of all variables, so it should arguably result in better climate projections for impact studies. Time series of any length can be generated with this method: another advantage for the study of rare events.

Acknowledgements. This work was partially supported by the Natural Science and Engineering Research Council of Canada (NSERC), Hydro-Québec, Manitoba Hydro and the Ouranos Consortium on Regional Climatology and Adaptation to Climate Change.

\section{LITERATURE CITED}

Apipattanavis S, Podesta G, Rajagopalan B, Katz RW (2007) A semiparametric multivariate and multisite weather generator. Water Resour Res 43:W11401 doi:10.1029/ 2006WR005714

> Caya D, Laprise R (1999) A semi-implicit semi-Lagrangian regional climate model: the Canadian RCM. Mon Weather Rev 127:341-362

Chen J, Zhang XC, Liu WZ, Li Z (2008) Assessment and improvement of CLIGEN non-precipitation parameters for the Loess Plateau of China. Trans ASABE 51:901-913

Chen J, Zhang XC, Liu WZ, Li Z (2009) Evaluating and extension CLIGEN precipitation generation for the Loess Plateau of China. J Am Water Res Assoc 45:378-396

Chen J, Brissette FP, Leconte R (2011) Uncertainty of downscaling method in quantifying the impact of climate change on hydrology. J Hydrol (Amst) 401:190-202

Chen J, Brissette FP, Leconte R (2012) Coupling statistical and dynamical methods for spatial downscaling of precipitation. Clim Change (in press)

DAI CGCM3 Predictors (2008) Sets of predictor variables derived from CGCM3 T47 and NCEP/NCAR reanalysis. Version 1.1. April 2008, Montreal

Diaz-Nieto J, Wilby RL (2005) A comparison of statistical downscaling and climate change factor methods: impacts on low flows in the river Thames, United Kingdom. Clim Change 69:245-268

Duan Q (2003) Calibration of watershed models. In: Duan Q, Gupta H, Sorooshian AN (eds) Water Science and Application, Vol 6. Washington, DC, p 89-104

Duan Q, Sorooshian S, Gupta VK (1994) Optimal use of the SCE-UA global optimization method for calibrating watershed models. J Hydrol (Amst) 158:265-284

Fortin V (2000) Le modèle météo-apport HSAMI: historique, théorie et application. Institut de Recherche d'HydroQuébec, Varennes

Groisman PY, Knight RW, Easterling DR, Karl TR, Hegerl GC, Razuvaev VN (2005) Trends in intense precipitation in the climate record. J Clim 18:1326-1350

Hutchinson MF, McKenney DW, Lawrence K, Pedlar JH, Hopkinson RF, Milewska E, Papadopol P (2009) Development and testing of Canada-wide interpolated spatial models of daily minimum-maximum temperature and precipitation for 1961-2003. J Appl Meteorol 48:725-741

IPCC (2007) Climate Change 2007: the physical science basis. Contribution of Working Group I to the Fourth Assessment Report of the Intergovernmental Panel on Climate Change. Cambridge University Press, Cambridge

Kilsby CG, Jones PD, Burton A, Ford AC and others (2007) A daily weather generator for use in climate change studies. Environ Model Softw 22:1705-1719

Music B, Caya D (2007) Evaluation of the hydrological cycle over the Mississippi River Basin as simulated by the Canadian Regional Climate Model (CRCM). J Hydrometeorol 8:969-988

> Music B, Caya D (2009) Investigation of the sensitivity of water cycle components simulated by the Canadian Regional Climate Model to the land surface parameterization, the lateral boundary data, and the internal variability. J Hydrometeorol 10:3-21

Nicks AD, Lane LJ (1989) Chapter 2: weather generator. In: Lane LJ, Nearing MA (eds) USDA-Water Erosion Prediction Project: Hillslope profile version. NSERL Report No. 2, USDA-ARS National Soil Erosion Research Laboratory, West Lafayette, IN

Nicks AD, Lane LJ, Gander GA (1995) Chapter 2: weather generator. In: Flanagan DC, Nearing MA (eds) USDAWater Erosion Prediction Project: Hillslope profile and watershed model documentation. NSERL Report No. 10, West Lafayette, IN

Pruski FF, Nearing MA (2002) Climate-induced changes in erosion during the 21st century for eight US locations. Water Resour Res 38(12):1298

> Pryor SC, Howea JA, Kunkelb KE (2009) How spatially coherent and statistically robust are temporal changes in extreme precipitation in the contiguous USA? Int J Climatol 29:31-45

Qian B, Hayhoe H, Gameda S (2005) Evaluation of the stochastic weather generators LARS-WG and AAFC-WG for climate change impact studies. Clim Res 29:3-21

Qian B, Gameda S, de Jong R, Falloon P, Gornall J (2010) Comparing scenarios of Canadian daily climate extremes derived using a weather generator. Clim Res 41:131-149

Richardson CW (1981) Stochastic simulation of daily precipitation, temperature, and solar radiation. Water Resour Res 17:182-190 
Richardson CW, Wright DA (1984) WGEN: a model for generating daily weather variables. USDA, Agricultural Research Service, ARS-8, Temple, TX

Rivington M, Miller D, Matthews KB, Russell G, Bellocchi G, Buchan K (2008) Evaluating regional climate model estimates against site-specific observed data in the UK. Clim Change 88:157-185

Sailor DJ, Li X (1999) A semi-empirical downscaling approach for predicting regional temperature impacts associated with climatic change. J Clim 12:103-114

Schoof JT, Pryor SC (2001) Downscaling temperature and precipitation: a comparison of regression-based methods and artificial neural networks. Int J Climatol 21:773-790

Schoof JT, Pryor SC, Surprenant J (2010) Development of daily precipitation projections for the United States based on probabilistic downscaling. J Geophys Res 115: D13106 doi:10.1029/2009JD013030

Semenov MA, Barrow EM (2002) LARS-WG: a stochastic weather generator for use in climate Impact studies. User manual, www.rothamsted.bbsrc.ac.uk/mas-models/ larswg.php

Solman S, Nunez M (1999) Local estimates of global climate change: a statistical downscaling approach. Int J Climatol 19:835-861

Trigo RM, Palutikof JP (2001) Precipitation scenario over Iberia: a comparison between direct GCM output and different downscaling techniques. J Clim 14:4422-4446

von Storch H, Zorita E, Cubasch U (1993) Downscaling of global climate change estimates to regional scales: an application to Iberian rainfall in wintertime. J Clim 6: 1161-1171

Widmann M, Bretherton CS, Salathé EP (2003) Statistical precipitation downscaling over the Northwestern United States using numerically simulated precipitation as a predictor. J Clim 16:799-816

Wilby RL, Wigley TML (1997) Downscaling general circulation model output: a review of methods and limitations.

Editorial responsibility: Richard Katz, Boulder, Colorado, USA
Prog Phys Geogr 214:530-548

Wilby RL, Wigley TML, Conway D, Jones PD, Hewitson BC, Main J, Wilks DS (1998a) Statistical downscaling of general circulation model output: a comparison of methods. Water Resour Res 34:2995-3008

Wilby RL, Hassan H, Hanaki K (1998b) Statistical downscaling of hydrometeorological variables using general circulation model output. J Hydrol (Amst) 205:1-19

Wilby RL, Dawson CW, Barrow EM (2002a) SDSM: a decision support tool for the assessment of regional climate change impacts. Environ Model Softw 17:145-157

- Wilby RL, Conway D, Jones PD (2002b) Prospects for downscaling seasonal precipitation variability using conditioned weather generator parameters. Hydrol Processes 16:1215-1234

Wilks DS (1992) Adapting stochastic weather generation algorithms for climate change studies. Clim Change 22: 67-84

Wilks DS (1999) Multisite downscaling of daily precipitation with a stochastic weather generator. Clim Res 11: 125-136

Wilks DS (2010) Use of stochastic weather generator for precipitation downscaling. WIREs Clim Change 1:898-907

Zhang XC (2004) CLIGEN non-precipitation parameters and their impact on WEP crop simulation. Trans ASAE 20:447-454

Zhang XC (2005) Spatial downscaling of global climate model output for site-specific assessment of crop production and soil erosion. Agric For Meteorol 135:215-229

> Zhang XC, Liu WZ (2005) Simulating potential response of hydrology, soil erosion, and crop productivity to climate change in Changwu tableland region on the Loess Plateau of China. Agric For Meteorol 131:127-142

Zhang XC, Nearing MA, Garbrecht JD, Steiner JL (2004) Downscaling monthly forecasts to simulate impacts of climate change on soil erosion and wheat production. Soil Sci Soc Am J 68:1376-1385

Submitted: March 23, 2011; Accepted: September 29, 2011 Proofs received from author(s): March 8, 2012 